\title{
A história da alfabetização de adultos no ensino, na pesquisa e na extensão da UFU e da UFMG (1986-2019)
}

The history of adult literacy in teaching, research and extension at UFU and UFMG (1986-2019)

La historia de la alfabetización de adultos en la enseñanza, la investigación y la extensión en UFU y UFMG (1986-2019).

\author{
Francisca Izabel Pereira Maciel \\ Universidade Federal de Minas Gerais (Brasil) \\ https://orcid.org/0000-0003-4751-2890 \\ http://lattes.cnpq.br/0925119698225692 \\ emaildafrancisca@gmail.com \\ Sônia Maria dos Santos \\ Universidade Federal de Uberlândia (Brasil) \\ https://orcid.org/0000-0002-7217-1576 \\ http://lattes.cnpq.br/9281057859793276 \\ soniaufu@gmail.com
}

\section{RESUMO}

Em um país, historicamente marcado pelos altos índices de analfabetismo - atualmente com 11,3 milhões de analfabetos- é possível constatar, por meio das pesquisas teóricas, como também nos profissionais da área da educação, que a EJA possui um lugar periférico nas políticas públicas, nas atividades, nas produções acadêmicas, principalmente no que diz respeito à alfabetização de jovens e adultos. Neste artigo, propomos uma reflexão sobre a história de alfabetização de adultos, a partir de Projetos desenvolvidos no campo do ensino, da pesquisa, e da extensão desenvolvidos em duas instituições federais, a Universidade Federal de Uberlândia (UFU) e a Universidade Federal de Minas Gerais (UFMG), desde a década de 80. O tripé das Universidades públicas são as atividades de ensino, pesquisa e extensão. Portanto, tematizar e refletir sobre a importância de projetos de extensão nas Universidades é o objetivo deste artigo. Nem sempre as atividades extensionistas são valorizadas nos meios acadêmicos e o mesmo ocorre quando se trata da educação de jovens e 
adultos. Neste artigo, duas pesquisadoras buscam narrar suas histórias de projetos de pesquisa e extensão vivenciadas no campo acadêmico da alfabetização de adultos. No caso da UFMG, foi criado um projeto de pesquisa, inicialmente, coordenado por professores da Faculdade de Letras, cujo objetivo era compreender o processo de aquisição da leitura e da escrita em adultos analfabetos. A partir de 1986, o projeto foi integrado à Faculdade de Educação, ampliado ao longo dos anos como um projeto de extensão, ensino e pesquisa de pósgraduandos da linha Educação e Linguagem do Programa de Pós-Graduação da FaE/UFMG. Refletir sobre a longa duração desse Projeto ajuda-nos a entender o lugar das universidades no processo educativo e no compromisso social que a academia deve ter com as camadas menos favorecidas e na socialização da produção dos conhecimentos acadêmicos. Quanto a UFU, o processo foi inverso ao da UFMG, pois nesta universidade, a EJA aparece inicialmente e de forma tímida na extensão com cursos isolados e uma sala de alfabetização de EJA onde há mais de 15 anos atende alunos com problemas psicossociais. Essa experiência foi se consolidando não só na extensão como também um dos campos de pesquisa sobre a história da alfabetização na EJA nas linhas do PPGED/FACED/UFU, e ainda nos cursos de aperfeiçoamento financiados pela SEB/MEC e SECADI/MEC, a partir de 2009.

Palavras-chave: EJA. História de alfabetização de adultos. Projetos de extensão. Universidade.

\section{ABSTRACT}

In a country historically marked by high illiteracy rates - currently with 11,3 million illiterates - it is possible to verify through theoretical research, as well with professionals form educational field, that EJA has a peripheral place in public policies, activities, academic productions, especially with regard to youth and adult literacy. In this paper, we propose a reflection about the history of adult literacy, based on projects developed in the field of teaching, research and extension at UFU and UFMG, since the 1980s. The tripod of public universities are teaching, research and extension activities. Thematic and reflecting about the importance of extension projects in universities is the objective of this paper. Extension activities are not always valued in academic circles, as well as the education of young people and adults. In this paper two researchers seek to narrate the history lived in the academic field of adult literacy, as for UFMG, initially a research project was created, coordinated by professors of the Faculty of Letters, whose objective was to understand the process of acquisition of reading and writing in illiterate adults. The project was expanded over the years as an extension project, teaching and research of post-graduate students of the Education and Language line of the Graduate Program of FaE/UFMG. Reflecting about the long duration of this Project helps us to understand the place of universities in the educational process and in the social commitment that the academy should have with the less favored layers and in the socialization of the production of academic knowledge. As for UFU, the process was inverse to that of UFMG, because in this university the youth and adult education appears initially and in a timid way in an extension project, with one isolated course focused in students with psychosocial problems, that has been working for last 15 years. This experience has been consolidated not only in extension, but also in the fields of research on the history of literacy in EJA under the PPGED / FACED / UFU lines, as well as in the financial improvement courses of SEB / MEC and SECADI / MEC from of 2009.

Keywords: EJA. History of adult literacy. Extension projects. Universities. 


\section{RESUMEN}

En un país históricamente marcado por altas tasas de analfabetismo -actualmente con 11,3 millones de analfabetos- es posible ver, a través de la investigación teórica, así como en los profesionales de la educación, que EJA tiene un lugar periférico en las políticas públicas, las actividades y la producción académica, especialmente en lo que respecta a la alfabetización de jóvenes y adultos. En este artículo proponemos una reflexión sobre la historia de la alfabetización de adultos, a partir de proyectos desarrollados en el campo de la enseñanza, la investigación y la extensión en dos instituciones federales, la Universidad Federal de Uberlandia (UFU) y la Universidad Federal de Minas Gerais (UFMG), desde los años ochenta. El trípode de las universidades públicas son las actividades de docencia, investigación y extensión. Por lo tanto, el objetivo de este artículo es discutir y reflexionar sobre la importancia de los proyectos de extensión en las universidades. Las actividades de extensión no siempre son valoradas en los círculos académicos y lo mismo ocurre cuando se trata de la educación de jóvenes y adultos. En este artículo, dos investigadores tratan de contar sus historias sobre proyectos de investigación y extensión experimentados en el campo académico de la alfabetización de adultos. En el caso de la UFMG, se creó un proyecto de investigación, inicialmente coordinado por profesores de la Facultad de Letras, cuyo objetivo era comprender el proceso de adquisición de la lectura y la escritura en adultos analfabetos. A partir de 1986, el proyecto se integró a la Facultad de Educación, ampliándose a lo largo de los años como un proyecto de extensión, enseñanza e investigación para estudiantes de postgrado de la línea de Educación y Lengua del Programa de Postgrado de FaE/UFMG. Reflexionar sobre la larga duración de este proyecto nos ayuda a entender el lugar de las universidades en el proceso educativo y en el compromiso social que la academia debe tener con las capas menos favorecidas y en la socialización de la producción de conocimiento académico. En cuanto a la UFU, el proceso fue el opuesto al de la UFMG, porque en esta universidad, la EJA aparece inicial y tímidamente en la extensión con cursos aislados y una sala de alfabetización de la EJA donde durante más de 15 años atiende a estudiantes con problemas psicosociales. Esta experiencia se consolidó no sólo en la extensión sino también en uno de los campos de investigación sobre la historia de la alfabetización en EJA en las líneas del PPGED/FACED/UFU, y también en los cursos de perfeccionamiento financiados por SEB/MEC y SECADI/MEC, a partir de 2009.

Palabras clave: EJA. Historia de alfabetización de adultos. Proyectos de extensión. Universidad. 


\section{Introdução}

Neste artigo, propomos analisar, pelo viés da historiografia, o lugar ou não lugar que a alfabetização de jovens e adultos ocupa nas Universidades, principalmente no que diz respeito aos projetos de extensão, de pesquisa e de ensino da EJA. Poderíamos recortar e analisar cada um dos segmentos citados, entretanto, neste texto, nossa proposta é analisar e descrever, historicamente, caminhos percorridos por duas universidades, a saber: um projeto de extensão desenvolvido na UFMG e na UFU, e seus desdobramentos nos lugares ou não lugares da EJA, nos cursos de licenciatura, na pós-graduação em educação e nas Pró-Reitorias de Extensão, Pesquisa e Ensino.

Do ponto de vista historiográfico, poderíamos indagar ou questionar se três décadas são um tempo relativamente curto ou longo. Isso torna-se relativo, quando tomamos como objeto de análise dois projetos de extensão de duas instituições mineiras, uma vez que o mais comum são projetos de extensão e/ou pesquisa terem a duração de três a quatro anos. Se considerarmos esse tempo de duração, tanto a UFMG como a UFU ultrapassaram essa barreira denominada por pesquisadores e estudiosos dessa área, como sendo "comum" o término dos projetos após 2 anos. No caso da UFMG, o Programa de Educação de Jovens e Adultos (PROEF 1), teve início em 1986, e é um projeto que fez e faz histórias. Na UFU, o projeto de EJA, foi elaborado para ser desenvolvido em espaços não escolares desde 2002, cujo objetivo era alfabetizar jovens e adultos com problemas psicossociais. Esses dois percursos, com semelhanças e diferenças, serão objeto de reflexão e análise neste artigo.

Nossas reflexões se pautaram nas nossas vivências nessa área - nosso lugar de trabalho e de pesquisa por mais de 25 anos -, em defesa da alfabetização de jovens e adultos no meio acadêmico: na pesquisa, no ensino e nos projetos de extensão.

Assim decidimos iniciar nossas reflexões, pontuando análises sobre a história da alfabetização de jovens e adultos: um campo marcado pela exclusão e inclusão nas universidades brasileiras.

\section{História da alfabetização de jovens e adultos: um campo marcado pela exclusão e inclusão nas universidades brasileiras}

A história da EJA, assim como da alfabetização de jovens e adultos no Brasil, revela o caráter assistencialista àqueles que não dominam a leitura e a escrita. As campanhas de alfabetização no Brasil são clássicos exemplos desse viés de oferta - doação - de algo que é um direito do cidadão brasileiro. Há uma nítida inversão de valores, provendo-os de uma atitude assistida, passiva, desprovida de conhecimentos, valores, cultura, etc.

A título de exemplo, traremos um fragmento de citação de uma conferência de Miguel Couto, realizada em 1927, na Associação Brasileira de Educação, sobre o tema: "No Brasil só há um problema nacional: a educação do povo". O título mostra o problema e aponta sua solução; o orador afirma que o problema [analfabetismo], uma vez resolvido, colocará o Brasil a par das nações mais cultas, dando-lhes proventos e honrarias e lhe afiançando a prosperidade e a segurança. Para alcançar esse objetivo, é necessário acabar definitivamente com o analfabetismo, pois "o analfabetismo é o cancro que aniquila o nosso organismo, com as suas múltiplas metástases, aqui a ociosidade, ali o vício, além o crime”. (COUTO, 1927, p.19, apud MACIEL, 1994).

Na mesma direção, Maciel (1994) destaca a fala do ex-ministro da Educação Carlos Chiarelli, enquanto ministro, em 1990, que, ao propor o Plano Nacional de Alfabetização fez a seguinte declaração: 
O plano tem como objetivo dar aos 30 milhões de brasileiros analfabetos o direito da cidadania, tirá-los da ignorância. (...) $O$ governo se mobiliza e quer o apoio da sociedade no combate à chaga como ferida infecta a macular a consciência dos homens e da nação. (FOLHA DE SÃO PAULO, 11/9/1990, p.A4, grifos nossos).

Pelas afirmações do Ministro da Educação, não era difícil prever que o plano representava mais uma tentativa fadada ao fracasso, tal como de fato ocorreu. Aliás, pode-se afirmar que as propostas governamentais em geral não têm surtido efeitos positivos; podemos dizer que, apesar de essas propostas representarem diferentes tendências políticas, elas apresentam alguns pontos em comum. O primeiro é que o analfabeto é nelas sempre estigmatizado como um "doente", uma "ferida infecta", um "câncer", uma "vergonha nacional". Basta comparar as palavras acima citadas do Ministro Carlos Chiarelli em 1990 com a de Miguel Couto em 1927 (MACIEL, 1994).

Os termos comuns associados ao analfabetismo e ao analfabeto são de erradicação, erva daninha, doença, câncer, e, como consequência, é comum as propostas assistencialistas para solucionar o grave problema nacional.

A história da alfabetização de jovens e adultos no Brasil comprova o descaso com que os Ministros da Educação veem a educação dessas pessoas, mesmo sabendo que cresce o número de jovens que abandonam a escola, antes mesmo de finalizar o ensino fundamental. Dados de $2017^{1}$ apontam que $62 \%$ dos jovens com idades de 15 a 17 anos não concluíram o Ensino Fundamental; e entre 2005 e 2015 , cresceu de $19 \%$ para $22 \%$ o número de jovens da 'geração nem, nem', jovens que nem estudam e nem trabalham. Esses dados e a falta de investimentos condizentes e adequados ao público emergente não são animadores e nos levam a crer, sem desejar que isso venha a ocorrer, que um contingente significativo desses jovens de hoje se tornará os analfabetos funcionais de amanhã e, novamente, serão discriminados e excluídos.

Se a EJA é para nós, pesquisadores e militantes dessa área, um espaço de busca constante em favor dos jovens e adultos analfabetos para ter o seu reconhecimento como cidadão, seu direito a aprender a ler e a escrever, esse processo não tem sido fácil, é longo, pois é complexo, e vem ocorrendo de forma gradativa ao longo do século XX. Tem sido muitas as lutas dos movimentos sociais e dos Fóruns de EJA, buscando alcançar sua plenitude na Constituição Federal de 1988, quando o poder público reconheceu a demanda de jovens e adultos que não concluíram sua escolaridade pelo direito aos cursos regulares. Para Haddad (2007), apesar desse reconhecimento de que toda a sociedade brasileira teria direito a uma escolarização, a história tem demonstrado limites na concretização desse direito, no contexto das reformas neoliberais nos anos seguintes.

No século XXI, 50 anos depois do lançamento do Programa Nacional de Alfabetização de Paulo Freire (1964), os dados ainda são alarmantes: pesquisas mostram que o analfabetismo entre a população de 15 anos ou mais, continua estagnado. Segundo dados da Pesquisa Nacional por Amostra de Domicílios Contínua (PNAD 2019), o número de analfabetos é de 11,3 milhões, o que corresponde a 6,8\% da população brasileira. Os números são expressivos, ou seja, o atendimento da EJA continua muito aquém do que poderia ser. Assim, segundo Gadotti (2014), uma pergunta ecoa historicamente: por que o número de analfabetos é hoje aproximadamente o mesmo de quando Freire realizou essa experiência, há mais de 50 anos? Várias são as razões para tal situação e, particularmente, duas são bem visíveis: muitos saem da escola semianalfabetos, com pouca competência linguística, e para colaborar com esse quadro, a escola brasileira, no decorrer da história, não acolheu de

\footnotetext{
1 Levantamento realizado pela ONG “Todos Pela Educação". Disponível em: <www.todospelaeducacao.org.br>.
} 
maneira coerente e justa os jovens e adultos egressos da fase de alfabetização. Com isso eles acabam regredindo ao analfabetismo. Desse modo, houve uma continuidade na história do analfabetismo no Brasil: o número de leitores não mudou; os analfabetos do passado tiveram poucas oportunidades de se tornarem cidadãos capazes de lerem e escreverem pequenos textos ou cartas, tão comum naquela época.

A complexidade do mundo impõe exigências educativas cada vez maiores para os trabalhadores e para os cidadãos. É fundamental, portanto, que a EJA considere a importância de que os educandos continuem aprendendo, seja dentro do sistema de ensino formal, seja aproveitando ou lutando por mais oportunidades de se desenvolverem como trabalhadores, como cidadãos e como seres humanos.

Nesse sentido, é importante considerar o que a historiografia nos tem apontado: ter o domínio da leitura e da escrita, fazer usos sociais dessas habilidades é uma de proporcionar a justiça social aos nossos jovens e adultos desprovidos dessa aprendizagem e é uma forma de dar legitimidade ao saber popular, garantindo o direito à escolarização, o acesso ao ensino de qualidade e ao efetivo exercício da cidadania. Não é novidade que o aluno da EJA, pertencente a uma modalidade educacional marginalizada ${ }^{2}$, "precisa ser incluído em práticas relevantes de uso da língua, via projeto de letramento" (KLEIMAN, 2000, p. 102), cujas atividades, centradas na linguagem, têm um potencial de subsidiar a formação de sujeitos letrados. Segundo Kleiman (1995), o resgate da cidadania, no caso dos grupos marginalizados, pouco escolarizados, passa necessariamente pela transformação de práticas sociais que os excluem, como as da escola.

Quando investigamos a história da EJA no Brasil e principalmente nas universidades brasileiras, não tem como se esquivar e não registrar a importância da constituição dos Fóruns de EJA do Brasil que, ao serem criados, tiveram como propósito dar visibilidade às ações tímidas da EJA. Desde a sua constituição, os Fóruns assumiram um importante papel de resistência, numa perspectiva de que "A participação popular é um processo efetivo de educação de adultos, pois fortalece a consciência da cidadania da população, para que ela assuma o seu papel de sujeito da transformação da cidade" (GADOTTI, 2000, p. 92).

Iniciado nos anos de 1990, diante da demanda e necessidade da preparação da V Confintea e das poucas ações das políticas públicas existentes neste período para a EJA propostas pelo Ministério da Educação-MEC, este movimento tornou-se na atualidade um locus permanente de reflexão, articulação e defesa da EJA no Brasil. Compreendido ora como um movimento social, ora como um espaço aglutinador das discussões e lutas políticas por uma melhor qualidade na educação destinada às pessoas jovens, adultas e idosas, os Fóruns de EJA no Brasil também são vistos como um espaço formador para aqueles que atuam nesta modalidade de ensino. (SANTOS et al., 2016, p.147-148).

Nesse contexto, os Fóruns no Brasil assumiram uma singularidade que lhe conferiu abrangência, relevância e influência na condução das políticas públicas para a EJA, tanto na esfera estadual como federal. Essas questões ainda carecem de investigações e debates na busca de reflexões que possam auxiliar a enxergar de fato o que são os Fóruns de EJA, para que vieram, como eles atuam politicamente nos estados e qual o seu papel e influência em âmbito nacional. (SANTOS et al., 2016). As universidades brasileiras têm um papel

\footnotetext{
${ }^{2}$ Só muito recentemente a modalidade EJA, que atende apenas a $6 \%$ da demanda total de cursos para alunos jovens e adultos, passou a receber financiamento do Fundo de Manutenção e Desenvolvimento da Educação Básica (FUNDEB).
} 
fundamental nesse processo: o de pensar junto com estado e municípios estratégias e táticas de resistência para enfrentar os desafios dessa área.

A Confintea realizada no Brasil fortaleceu e confirmou a importância dos Fóruns de EJA no país, como movimento social, na militância por uma EJA para todos e todas, e com qualidade social, na crença de que

a educação de adultos é um processo que ainda vivencia uma fase de esclarecimento terminológico e conceitual e que tem sofrido contínuas crises de legitimidade. É de grande ajuda que as comunidades de nações e os representantes governamentais responsáveis por este setor da educação possam reunir-se com especialistas e organizações não governamentais, sob a égide da UNESCO, para intercambiar informações, examinar o estado das coisas e analisar quais são os passos para determinar e planejar visando a um futuro comum (UNESCO, 2009, p.10).

Santos et al. (2016), afirma ainda que,

a compreensão de que juntos precisamos estar e pensar tem movido as instituições, organizações e grupos que atuam na EJA, em especial os Fóruns de EJA, e alimentado as discussões na área da educação das pessoas jovens, adultas e idosas no país, num processo de vigilância e luta. (SANTOS et al., 2016, p. 152).

Nesse movimento nacional, a UFU criou o TRIEJA em 2007, conhecido como o FÓRUM de EJA do Triângulo Mineiro. Esse fórum deu vida às políticas públicas e inserção da EJA na academia. A título de exemplo, são ações desenvolvidas pelo TRIEJA: 11 Fóruns de EJA de 2007 a 2016, 1 Fórum Mineiro de EJA em 2013, 1 curso de Aperfeiçoamento EJA na Diversidade - na modalidade EAD ofertado em 2009, 1 curso para Produção de Material Didático e Formação de Mediadores de Leitura em 2014, 1 curso de Especialização em EJA na Diversidade e Inclusão Social - 2 turmas em Uberlândia e 1 em Ituiutaba, 2 cursos de Especialização em EJA para Juventude - 1 turma em Uberlândia - 2 turmas em Monte Carmelo, 3 cursos de Especialização em EJA para Juventude II - 1 turma em Uberlândia e 1 turma em Ituiutaba, 4 cursos de Especialização em Docência no Ensino Médio: Diversidade, Inclusão e EJA - 1 turma em Uberlândia e 1 turma em Ituiutaba de 2014 a 2017, 2 pesquisas financiadas pela Capes e Fapemig: O letramento e a prática pedagógica dos professores de EJA nos anos de 2010 - 2012 e 2013 - 2016. É importante ressaltar que os cursos de especialização 1 e 2 especificados acima geraram mais de 200 Trabalhos de conclusão de curso - TCCs - produzidos e apresentados em seminário coletivo sobre a EJA.

Magda Soares (2003) também defende que a universidade tem que se filiar à luta contra as discriminações e as exclusões. A universidade deve desenvolver reflexões sobre aquilo que se oculta sob as concepções do senso comum a respeito das relações alfabetizaçãocidadania, desnudar essas concepções de seu conteúdo ideológico e de aceitação histórica do descaso pela alfabetização de jovens e adultos no Brasil:

À universidade cabe, por excelência, buscar, através da reflexão e da pesquisa, a produção de um conhecimento que conduza a uma alfabetização que, além de inserir realmente o adulto na cultura letrada, faça-o de forma que essa inserção não seja uma assimilação 
passiva dessa cultura, mas represente novas possibilidades de avançar na luta pela conquista da cidadania. (SOARES, 2003, p.32).

Como pesquisadoras dessa área, podemos afirmar que o Brasil e, por consequência, as universidades têm uma dívida republicana com os jovens e adultos analfabetos do nosso país. A década de 80 foi um momento marcado pelo fortalecimento da sociedade civil, principalmente nos setores comprometidos com as classes populares. Nesse contexto, muitas universidades buscaram redefinir as bases que orientam as ações de ensino, pesquisa e extensão. O projeto Alfabetização de Adultos da UFMG surge, portanto, nesse contexto de mudança do papel da extensão acadêmica, não mais centrada no assistencialismo, e, sim, na articulação com o ensino e a pesquisa, por meio da organização e assessoria dos movimentos sociais que emergiam.

O Projeto de Educação de Jovens e Adultos da UFMG, atualmente, denominado Programa de Educação Básica de Jovens e Adultos da UFMG, abrange os três segmentos da Educação de Jovens e Adultos (EJA), desdobrados em três projetos: Projeto de Educação de Jovens e Adultos $-1^{\circ}$. Segmento (PROEF1), Projeto de Educação de Jovens e Adultos $-2^{\circ}$. Segmento (PROEF 2) e o Projeto de Ensino Médio de Jovens e Adultos (PROEMJA). A criação desses projetos ocorreu em meados da década de 80 do século XX. Soares (2016) apresenta o histórico do Projeto de Educação de Jovens e Adultos - segundo segmento - PROEF2, criado no

Centro Pedagógico da Universidade Federal de Minas Gerais como um projeto de extensão, denominado Curso Supletivo, para atender inicialmente aos funcionários que trabalhavam na Universidade e não haviam concluído o então denominado primeiro grau. (SOARES, 2016, p.43).

O projeto de Educação de Jovens e Adultos - Ensino Médio (PROEMJA) veio se consolidar em consequência da demanda dos alunos concluintes do Ensino Fundamental em dar continuidade aos seus estudos. Os três projetos constituiem, atualmente, o Programa de Educação de Jovens e Adultos da UFMG, abrangendo todos os segmentos da EJA. Desde a sua criação, esse Projeto na UFMG se constituiu com práticas mais autônomas e um currículo interdisciplinar e já se diferenciava dos demais cursos supletivos existentes ${ }^{3}$. E o PROEMJA ${ }^{4}$ veio em consequência do término da escolaridade do público do PROEF2 que pleiteava prosseguir seus estudos e, consequentemente, concluir o ensino médio.

Um pouco diferenciado dos projetos anteriores (PROEF2 e PROEMJA), o início do PROEF1se deu a partir de uma pesquisa coordenada por professores da Faculdade de Letras ${ }^{5}$. O projeto denominado Alfabetização de Adultos tinha como objetivo investigar sobre os conhecimentos linguísticos dos adultos em processo de alfabetização na construção de seus conhecimentos sobre a escrita. Todos os sujeitos da pesquisa eram funcionários da universidade. Da pesquisa iniciada, em 1986, com uma turma-piloto composta de onze trabalhadores da UFMG, o projeto foi se consolidando em um projeto de pesquisa, ensino e extensão, ampliando para atender também ao público externo à UFMG. A consolidação da pesquisa aconteceu com a inserção de novas turmas de alunos e reformulações da proposta inicial pelo grupo de pesquisadores e as contribuições de pesquisas de linguistas,

\footnotetext{
${ }^{3}$ Para maior aprofundamento sobre os 30 anos do PROEF2, ver: Soares, Leôncio, 2016.

${ }^{4}$ Atualmente, em 2019, o PROEMJA funciona nas dependências do Centro Pedagógico junto com o PROEF2.

${ }^{5}$ Sob a coordenação da Professora Eunice Maria das Dores Nicolai, o grupo de pesquisadores era composto pelos professores Daniel Alvarenga, Maria da Graça Costa Val, Milton do Nascimento, Orlando Bianchini.
} 
sociolinguistas. E, a partir 1994, o projeto foi integrado à Faculdade de Educação, coordenado pelo professor Daniel Alvareng ${ }^{6}$. A partir de 1997, pesquisadores do Centro de Alfabetização, Leitura e Escrita (Ceale) assumem a coordenação do PROEF1, e é por essa razão que a história do PROEF 1 será o recorte da UFMG neste artigo, uma vez que a abordagem do dossiê está centrada na alfabetização.

$\mathrm{Na}$ UFU, o projeto de extensão de "EJA em espaços não escolares", foi proposto tardiamente, em 2003. A EJA não era prioridade nessa universidade: o único curso que tem essa área como campo de conhecimento é o curso de Pedagogia, que inicialmente garante estudos optativos e, só em 2005, a área é contemplada com uma disciplina obrigatória de 90 horas no seu currículo. Dessa experiência de ensino na licenciatura, que não tinha a EJA como campo para estágio, que foi proposto o projeto de extensão para que os alunos do $4^{\circ}$ ano do curso de Pedagogia da UFU pudessem conhecer o sujeito da EJA na sua plenitude, experienciar o planejamento, a prática de sala de aula e a diversidade no sentido lato da palavra.

A sala de EJA desse projeto de extensão tem seu início nas dependências do Centro de Atendimento Psicossocial - CAPS. Atendíamos inicialmente jovens e adultos que estavam em tratamento. Depois de um semestre nesse espaço físico, decidimos, em conjunto com outros professores, alunos do curso de Pedagogia, assistente social e psicóloga, que faríamos um teste na UFU no campus Santa Mônica, local próximo ao CAPS, para ver se os alunos se adaptariam ao local e se as aulas pudessem ser mais interessantes para esses alunos em tratamento. A experiência foi exitosa, pois ir para o campus universitário arrebentou amarras, que dificilmente, no espaço físico de tratamento, conseguiríamos. Foi como se eles recebessem um aval de liberdade provisória, e cada conquista era muito comemorada, por todos: conquistas pequenas para nós, mas infinitamente grande e difícil para os jovens e adultos, que só sabiam um único trajeto: casa-clínica, clínica-casa. Os alunos iniciaram um processo de alforria e independência que se iniciou com um novo trajeto: ir e voltar do campus, na maioria das vezes, de ônibus, ou a pé.

Vencido esse desafio, foi necessário conhecer mais esse sujeito, o que ele sabia e como ele aprendia. Esse, com certeza, foi o desafio mais difícil, mas compensador. Como não precisávamos ter a rigidez da escola tradicional, tivemos tempo de aprender com eles e eles conosco. Nessa experiência, descobrimos que, para estar na EJA, exige-se conhecimento, militância e luta constante, pois, à medida que os jovens e os adultos circulavam pelo campus e pelo bloco $\mathrm{G}$, espaço esse que abrigava professores do curso de Pedagogia da UFU e coordenações administrativas da Faculdade de Educação, houve inicialmente um certo estranhamento: pois quem eram aquelas pessoas tão simples que circulavam nos corredores desse bloco na UFU? Aos poucos, alunos e professores da FACED foram aprendendo a conviver e a respeitar-se mutuamente.

Esse projeto de extensão foi proposto com data de início e fim, assim como acontece com todos os projetos de extensão e pesquisa. Entretanto, para nossa surpresa, o projeto funciona até hoje, perdura e persiste, mesmo sem ter apoio financeiro. A coordenação geral do projeto assumia junto com os estagiários, todos os voluntários, as despesas de xerox e lanches. A Faculdade de Educação da UFU doava também materiais de consumo que sobravam de outros projetos de extensão. Pode parecer estranho, mas todos os projetos da sala de EJA foram enviados aos diferentes editais da UFU e nenhum deles foi aprovado. O Grupo de pesquisa da Professora Sônia Santos, adotou essa sala, pois ela foi e continua sendo fonte de inspiração para novas investigações. Assim, não paramos de lutar a favor das desigualdades no nosso país e na academia (SANTOS, 2016).

Esse breve contexto do Programa da UFMG e do projeto da UFU nos permite refletir sobre a viabilidade, longevidade e integração de projetos de pesquisas, extensão e docência no campo da EJA. Um primeiro ponto a ser destacado nessa reflexão diz respeito ao conceito de extensão.

\footnotetext{
${ }^{6}$ Mesmo com o falecimento do Prof. Daniel Alvarenga, em 1997, o PROEF1 continuou na FaE/UFMG
} 
Refletindo sobre a função que a extensão pode ter na oferta e de como isso ainda acontece nos meios acadêmicos, consideramos pertinente trazer um fragmento de uma de obra de Paulo Freire, pouco divulgada: Extensão ou Comunicação? Esse livro foi inicialmente publicado no Chile, em $1969^{7}$, durante o exílio de Freire no país. É interessante o ponto de partida de Freire para trazer à tona os problemas que envolvem os trabalhos na extensão, identificados no contexto da reforma agrária chilena e no contexto educacional brasileiro, com reflexões ainda presentes na contemporaneidade.

Freire (1985) parte de uma discussão semântica e linguística do termo extensão, para alertar-nos sobre as armadilhas em que podemos cair - ou que assumimos - nas ações educacionais extensionistas, na medida em que "no termo extensão, está implícita a ação de levar, de transferir, de entregar, de depositar algo em alguém, uma conotação indiscutivelmente mecanicista" (FREIRE,1985, p.15). Infelizmente, é comum encontrarmos propostas extensionistas na EJA, com essa concepção e é, ainda mais grave, quando direcionadas aos analfabetos, propostas essas consoantes aos discursos de pesquisadores, políticos e ministros da educação.

Freire, já na década de 1980 nos alertava sobre as possibilidades de que a ação extensionista envolve "um conjunto de procedimentos técnicos, que implicam o conhecimento, que são conhecimento, se impõem as perguntas". (FREIRE, 1985, p.15, grifos nossos). E, ao assumirmos nosso compromisso social, assumimos também que nossas ações venham acompanhadas de uma postura que favoreça e instigue o conhecimento.

São as perguntas que propiciam o conhecimento, que, por sua vez, só ocorrem frente a uma postura curiosa. Portanto, não há conhecimento transformador sem curiosidade. É preciso sair da consciência ingênua. (FREIRE, 1985). Assim como Paulo Freire, Magda Soares também nos instiga com frequência a fazer perguntas de modo que possamos intervir, alterar, mudar a realidade brasileira (MACIEL, 2018).

Esses autores ajudam-nos nas reflexões em torno dos projetos de extensão, implicado de críticas por parte de colegas da academia. Em geral, constata-se o pouco entendimento do que deva ser um projeto de extensão, considerado por muitos como de pouco valor científico. Não há dicotomia, oposição entre os projetos de extensão e os "acadêmicos". A história desse Programa na UFMG e do projeto de extensão da UFU vem comprovar que é possível e desejável articular o tripé: ensino, pesquisa e extensão. E um primeiro passo nessa direção é a concepção de extensão, que, por sua vez, orienta o planejamento e execução do projeto.

Um segundo ponto para a ação bem-sucedida é o apoio dos órgãos competentes na execução do projeto. Devido à longevidade, que um projeto dessa natureza demanda, pelo fato infelizmente de termos um número expressivo de analfabetos e pessoas pouco escolarizadas é necessário contar com o apoio financeiro e logístico da Universidade. Diferentemente de outros projetos e de campanhas de educação de massa, ou programas governamentais como foi o Mobral, a Alfabetização Solidária e o Programa Brasil Alfabetizado, todos finalizados com uma população ínfima de alfabetizados, os projetos da UFMG e da UFU são de longa duração: não é por acaso que um foi iniciado em 1986 e o outro em 2002, e ambos continuam sendo desenvolvidos.

Na UFMG, o apoio da universidade na garantia das bolsas anuais dos monitores foi e é imprescindível. Contar com bolsistas anualmente deve ser um compromisso social e educacional a ser assumido por todas as universidades brasileiras. Ao contrário, na UFU o projeto sobrevive, há 16 anos, do que sobra de outros grandes projetos financiados. Os professores alfabetizadores são alunos do curso de Pedagogia que, a duras penas, buscam a cada ano validar as horas trabalhadas para convalidar como estágio de EJA.

\footnotetext{
${ }^{7}$ No Brasil, no ano de 1985.
} 
Mesmo contando com apoio financeiro da UFMG, os esforços empreendidos para a construção de um fazer coerente e fundamentado teoricamente não representaram para os jovens e os adultos do programa uma trajetória linear e sem percalços. A constituição do Projeto de Educação de Jovens e Adultos, denominado por nós de primeiro segmento - o PROEF1. Assim deve ser entendido numa dimensão processual e complexa, uma vez que as tentativas de consolidar as suas atividades foram marcadas por momentos de avanços e de recuos, constituição essa determinada, entre outros fatores, pelas possibilidades de limites dos participantes envolvidos nesse percurso.

A possibilidade de se ter Programas e Projetos de Extensão no campo da EJA abre uma alternativa para que os alunos possam conhecer e atuar na sala de aula. Partindo do princípio de que é função das universidades públicas desenvolver e apoiar propostas dessa natureza, nos projetos desenvolvidos nas duas Universidades, acreditamos que a aquisição e o domínio da língua materna é um instrumento fundamental para a participação política e a luta contra a marginalização, e o preconceito às pessoas analfabetas. Concordamos com Soares (2003, p.79): "ensinar por meio da língua e, principalmente, ensinar a língua são tarefas não só técnicas, mas também políticas". É necessário, portanto, que haja uma opção política coerente na escolha das teorias e metodologias que fundamentem e orientem a prática pedagógica, na busca de uma competência que combata, também, os discursos da neutralidade na educação, tão bem expressa e defendidas nas obras de Paulo Freire.

\section{O campo da leitura e escrita na história da EJA}

Do lugar de professoras universitárias que também é um lugar de aprendiz, procuramos os significados das vivências que nos constituíram como profissionais da educação. Nesse contexto de busca, somos influenciadas pela obra de Machado de Assis. Diferentemente de Brás Cubas, personagem que escreve suas memórias depois de morto, temos a nosso favor a possibilidade de rememorar no presente, enquanto a dinâmica da vida nos permite o contar, o recontar, e o reviver. Nesse pressuposto, recorremos a Magda Soares ${ }^{8}$, para fundamentar o sentido que seguirá nossa narrativa: "procuro-me no passado e "outrem" me vejo; não encontro a que fui, encontro alguém que a que sou vai reconstruindo, com a marca do presente. $\mathrm{Na}$ lembrança, o passado se torna presente e se transfigura, contaminado pelo aqui e o agora" (SOARES, 2001, p. 37).

Os princípios teórico-metodológicos sobre alfabetização e letramento que orientavam as práticas tanto no PROEF1 da UFMG como também no projeto de extensão da UFU a proposta didática tinha como pressuposto um processo dinâmico, que se fez e refez enquanto foi desenvolvido. E não podemos perder o foco de ensinar, sim, o sistema alfabético de escrita, isto é, as correspondências fonema-grafema e o sistema ortográfico, mas fazê-lo no contexto de e por meio de práticas sociais reais de leitura e escrita. Alfabetizar e letrar, letrar e alfabetizar significa não dissociar a aquisição da tecnologia da escrita das práticas sociais de leitura. A ideia básica do letramento é a de que a alfabetização, por si só, é insuficiente, pois o adulto não tem só de aprender a ler, mas deve aprender, também, a fazer uso da leitura e da escrita ${ }^{9}$.

Os projetos e as atividades para o ensino e a consolidação das turmas do PROEF1 da UFMG e do projeto de extensão da UFU eram e continuam a ser discutidas, planejadas e

\footnotetext{
${ }^{8}$ Quando nos referimos à autora Magda Becker Soares, optamos por empregar o nome e sobrenome, ou seja, Magda Soares. Quando nos referirmos ao autor Leôncio José Gomes Soares, faremos uso apenas do sobrenome Soares.

${ }^{9}$ Magda Soares e Paulo Freire defendem e se afinam em querer que todas as pessoas aprendam a ler e a escrever, dominar a técnica de forma consciente como ferramenta de transformação. Esse posicionamento é frequente na produção dos autores, o que torna difícil escolher citações de ambos para dialogar com meu texto, sem me tornar piegas, panfletária.
} 
organizadas a partir de atividades diagnósticas de leitura, escrita e conhecimentos matemáticos, e em função das demandas trazidas pelas monitoras - UFMG, e na UFU pelos professores de EJA junto às turmas de alfabetização e de consolidação da alfabetização. Nesse sentido, os encontros se constituíram e se constituem em momentos de discussão dos problemas que surgem no decorrer do processo ensino-aprendizagem, de planejamento, de avaliação e de reflexão das práticas.

A relação entre os monitores/professores e as coordenações iniciam-se no momento do processo seletivo. As inscrições são abertas para todos os cursos de licenciaturas da UFMG, na UFU selecionamos somente alunos do curso de Pedagogia. Na UFMG, em geral, predominam inscritos do curso de Pedagogia. Ao selecioná-los, procuramos identificar nos (as) candidatas(os) algumas qualidades de solidarizar-se com os adultos pouco escolarizados e muitos analfabetos, encarar as dificuldades como desafios, a confiança na capacidade de todos de aprender e ensinar. Em um modelo processual coletivo de formação, monitores e coordenadores vão construindo sua prática educativa junto aos educandos da EJA.

Nossa experiência na UFU com a leitura e a escrita dos alunos revelava nos seus textos uma vida sofrida, marcada pelo trabalho infantil, que os fez abandonar a escola, e alguns tiveram que abandonar suas famílias muito cedo, por agressões de familiares ou de pessoas próximas devido à não compreensão dos problemas advindos da infância, maustratos, alcoolismo dos pais, estupro feito por parentes próximos, familiares ou vizinhos e morte. Toda essa amálgama de problemas sociais e psicológicos somados à discriminação tornaram nossos alunos mais excluídos ainda, pois apresentam dificuldades para entender as dinâmicas da nossa sociedade, injusta, cruel, discriminatória e racista.

\section{Os monitores/professores e os educandos da UFMG e da UFU}

Atualmente, são poucos os cursos de Pedagogia que oferecem a formação do Educador de Jovens e Adultos. Na maioria desses cursos prevalece a oferta no currículo de apenas uma disciplina de EJA, como a história da UFU nos revela. E os alunos de outras licenciaturas, que ambicionam conhecer e estudar sobre a EJA nas universidades encontram pouco espaço para esses conhecimentos. As recentes pesquisas de Bernardes (2016) e Lepick (2018) revelam que nem como optativa a disciplina de EJA aparece nos currículos da maioria das universidades brasileiras, o que reflete o descaso das políticas e desinvestimentos no campo da EJA e, menos ainda, os conhecimentos sobre as obras de Paulo Freire.

Aqui está um dos motivos pelos quais defendemos com base na história da exclusão, a necessidade de haver disciplinas com carga horária adequada para a formação do profissional que vai atuar na EJA. Uma das hipóteses para o pouco interesse dos alunos da Pedagogia, no que se refere à formação em EJA, que acabam por escolher outras áreas do ensino, está diretamente ligada às políticas públicas educacionais brasileiras.

Ao longo desses anos à frente da coordenação do PROEF1 na UFMG e de projetos de extensão, pesquisa e ensino na UFU, são muitos os episódios, os relatos e os projetos pedagógicos desenvolvidos anualmente. Torna-se impossível não trazer as vozes dos educandos em um texto que se propõe justamente refletir sobre as relações entre universidade, extensão, ensino, pesquisa, em uma perspectiva cidadã.

$O$ fato de eles serem recebidos e cadastrados como alunos da UFMG e da UFU é sentido pelos educandos como um grande diferencial. É comum eles dizeres que estudam na UFMG e na UFU e como se orgulham em dizer que estudam nesse espaço, o que é verdadeiro, mesmo que não tenham que especificar que são alunos de EJA.

Alegam que é bom ir para a Universidade, "as salas são iluminadas, tudo funciona, as pessoas os tratam bem, têm consideração por eles...”. É possível entender por que consideram o 
bom funcionamento das escolas. Para a maioria, as lembranças do passado escolar são marcadas por maus-tratos até físicos, uma das causas do abandono escolar quando crianças. Enquanto adultos, ao retomar o processo de escolarização, enfrentam muitas dificuldades, a começar pelos locais pouco iluminados, materiais didáticos e mobiliários inadequados aos adulto. É comum encontrarmos adultos em salas com mesas e cadeiras para crianças. E um dos aspectos mais importantes para os educandos é se sentirem bem onde estiverem. Aprender envolve interação, empatia, comunicação e a linguagem, o diálogo oral e corporal são importantíssimos quando se trabalha com a EJA. O olho no olho, o aperto de mão, os sorrisos fazem toda a diferença na e para a aprendizagem dos jovens e adultos. E essa é uma aprendizagem que pode e deve ser ensinada, aprendida e vivenciada por todos na Universidade, ainda que para muitos, isso não seja considerado como conhecimento acadêmico.

Segundo Fontana (2003), nos tornamos professores mediante a multiplicidade de experiências e relações vividas no cotidiano, entendido como espaço e tempo de construções históricas, sociais e culturais. Muitas vezes, nos identificamos nos percursos de outros devido às determinações históricas da conjuntura social da qual fazemos parte. Contudo, o modo como interpretamos essas vivências é singular, configura-se no movimento pelo qual os sujeitos reinventam sentidos e significados para acontecimentos vividos no coletivo. Para Fontana (2003):

O processo em que alguém se torna professor(a) é histórico, ensinanos ela, mesmo sem o pretender. Na trama das relações sociais de seu tempo, os indivíduos que se fazem professores vão se apropriando das vivências práticas e intelectuais, de valores éticos e das normas que regem o cotidiano educativo e as relações no interior e no exterior do corpo docente. (FONTANA, 2003, p. 48).

Assim, nesse movimento, vamos nos formando e nos apropriando de vivências teóricas e práticas. No ano de 2016, dois alunos do $4^{\circ}$ ano do curso de pedagogia da UFU fizeram uma proposta de registrar as histórias dos alunos de EJA em um "Caderno de memórias", que teve como um dos seus pressupostos conhecer as histórias desses sujeitos, suas visões de mundo, e com isso também foi possível acompanhar o desenvolvimento do processo de alfabetização e letramento deles.

Ressaltamos aqui a narrativa de um estagiário da UFU, que revela que, no percurso das avaliações processuais e formativas, utilizou a observação e as rodas de conversa: "foi desta maneira que os alunos da EJA, também nos avaliaram, pois sempre buscávamos ouvilos a fim de compreendê-los, e conhecer o que eles tinham aprendido com as aulas. Foi em um processo de paciência e escuta sensível que entendíamos suas propostas e necessidades, assim podemos afirmar que a atuação neste projeto, somado às aulas no curso de Pedagogia que foram ministradas durante o ano de 2016, trouxe primeiramente a nós não só contribuição intelectual, formativa, mas, principalmente, humana, o que auxiliará não só na nossa profissão de professor, mas especialmente nas nossas vidas em geral Quanto aos alunos, podemos de forma singular afirmar que foi a melhor vivência propiciada no e pelo curso de pedagogia da UFU" (Memórias da EJA em espaços não escolares, 2016).

Com base nessa compreensão, desenvolvemos nossas pesquisas, projetos de extensão e ensino, considerando nosso interesse em compreender as concepções, as representações e as práticas das estagiárias e professoras alfabetizadoras de jovens e adultos - sujeitos esses produtores e receptores de cultura. 


\section{Histórias que não estão nos discursos dos políticos, governantes e bem distantes das políticas públicas}

Como este texto é uma tentativa de se configurar como um artigo histórico, optamos por produzir narrativas e depoimentos, uma vez que o uso das fontes orais tem possibilitado a nós, historiadores, "[...] mergulhar nos detalhes da história, em sua humanidade, evitando que se perca a memória das pessoas - verdadeiros agentes do processo histórico" (BARROS, 2004, p.48). Isso nos permite interpretar o presente com base no entendimento de singularidades históricas de um passado que ainda vive; porque relembrar acontecimentos com a experiência enriquecida pelo decorrer do tempo é uma forma possível de analisar com outro olhar a mesma situação.

A memória faz parte de um processo dinâmico que nos possibilita compreender os significados que vão reestruturando os elementos lembrados, no sentido de reordená-los, conservá-los ou excluí-los, alimentando-se de lembranças, às vezes, vagas ou até mesmo contraditórias, o que a torna ainda mais rica. São conhecimentos, fontes, matérias-primas da história e têm como tarefa reconstruir o passado, mas também são experiências que se vive no mundo íntimo, que permitem relacionar o presente com o passado e, ao mesmo tempo, interferir no processo atual das representações.

A história de Antônio, ex-aluno da UFMG, é comum a tantos outros alunos da EJA, nascido e criado na zona rural, chega à capital em busca dos sonhos de conquistar um bom emprego, salário digno, carteira assinada, trabalho fichado. Antônio consegue um "bom trabalho como porteiro de uma escola...". Nesse trabalho, como nos disse, ele entrou em crise, e não se cansava de dizer: "isto não está certo? Não está certo, não pode ser! Como posso trabalhar em uma escola, vendo aquele mundo de crianças estudando, sabendo ler e escrever e eu não sei ler nem escrever o abc? Isso não pode!" E repetia as frases com certa indignação e revolta. E foi com esses sentimentos que procurou o PROEF1.

Maria Helena narra que não queria ser novamente hospitalizada pela falta de leitura. Estranhamos essa fala dela, e ficou clara quando nos explicou que trabalhava como faxineira de uma fábrica de tintas, realizava limpeza bruta de salas, mobiliários, banheiros e era responsável por retirar resíduos de tintas dos maquinários e do chão. Trabalhava há muitos anos nesse serviço e usava diversos produtos de limpeza, todos seus velhos conhecidos, até o momento em que a empresa resolveu padronizar as embalagens dos produtos. Aí veio a dificuldade. "Como identificar se as embalagens e os rótulos eram todos iguais? As letras? Eu não sabia decifrar..., antes eu sabia pelas embalagens, cada uma de um jeito (formato), desenhos, cores de cada um”. Para não perder o emprego passou a identificar os produtos pelo aroma, passou a tentar identificá-los pelo cheiro, mas acabou intoxicada e levada às pressas para o pronto-socorro. Maria Helena nos traz uma necessidade de aprendizagem da leitura e da escrita como forma de preservação de sua vida! Não almejava um diploma, não ambicionava mudar de emprego, ter ascensão social, nada disso: aprender a ler e a escrever era uma forma de preservar a sua vida!

Assim como Maria Helena, Eliane trouxe suas preocupações com a falta da leitura em seu trabalho. Como cuidadora de idosos, sempre nos trazia o questionamento: "como cuidar dos velhinhos, dar o remédio certo, na hora certa, se eu não sei ler? Posso até matar um deles se não dou o remédio certo. Isso não pode acontecer. É a vida deles, eu amo esses velhinhos, eles são a minha vida! Eu tenho compromisso com a vida deles. A vida deles está em minhas mãos!!!" O desejo de aprender a ler e a escrever, estava posto para Eliane na sua responsabilidade pela vida dos idosos. Que lição de cidadania Eliane nos dá.

Histórias como as de Maria Helena, Eliane e Antônio nos fazem também refletir sobre nossa atuação, compromisso pedagógico, social e político. São Antônios, Elianes, Marias que vêm tanto para a UFMG como para a UFU encontrar o que durante muitos anos lhes foi negado: o seu direito de aprender a ler e a escrever. 
Nesse movimento de ouvir, registrar e acompanhar os programas e os projetos que as coordenadoras dos projetos da UFMG e da UFU visitavam às salas de aula, para ver os alunos, conversar sobre algum assunto específico ou com o objetivo de ouvi-los. Em uma dessas idas à UFMG, alunos de uma turma estavam todos alegres, e disseram que agora estava tudo muito bom. Entusiasmados, foram mostrando o caderno cheio de escritas. "Agora sim, estamos aprendendo de verdade", "olha como o caderno tá cheio". Então questionei-lhes o tempo que estavam gastando para copiar e resolver as atividades. Pedi que olhassem o caderno antes de se ter o problema nas reproduções - xerox - das atividades, a quantidade que faziam em um dia de aula. Pedi-lhes que contassem as atividades de um dia com e outro sem as reproduções coladas nos cadernos. Não demorou para concluírem que estavam "deixando de aprender mais". "A gente está gastando quase toda aula para copiar e pouco tempo para resolver os exercícios". Saio da sala com uma recomendação: "A senhora - é assim que se dirigem a mim - precisa dar um jeito de arrumar logo a máquina de xerox." Esse episódio nos mostra de como a cultura escolar, o modelo escolar tradicional está impregnado na memória dos nossos alunos da EJA.

Ajudá-los a refletir sobre diferentes situações tem nos revelado muito sobre o que pensam e como as discussões e reflexões coletivas ajudam a rever posicionamentos. A seguir, trazemos uma dessas discussões ocorridas na turma de Alfabetização da monitora Thuane, da UFMG, no ano de 2016. O debate começou a partir de uma reportagem levada pela monitora sobre a temática trabalho infantil. De imediato, manifestaram-se favoráveis ao trabalho infantil e todos os argumentos eram apoiados em suas histórias de vida. Cada um trazia a sua infância marcada pelo trabalho na roça, na construção, em casas de família, lavando roupas etc. Diziam que trabalharam desde cedo; o trabalho os fez homens e mulheres de responsabilidades. Por que lhes faria mal se todos eles estavam ali? Trabalhar cedo não matava ninguém. E assim foram construindo um discurso uníssono em torno da defesa do trabalho infantil.

A monitora deixou que apresentassem os argumentos e, em determinado momento, perguntou-lhes: 'quais as desvantagens de se trabalhar na infância?" Como estavam convictos das vantagens, a monitora foi mais incisiva e lançou a pergunta: "por que eles estavam no PROEF1?" E a resposta veio também em coro: "porque a gente trabalhava..." Foi muito interessante o relato da monitora de como eles se deram conta de que o trabalho na infância foi o principal fator que os afastou da escola. Em geral, eles têm conhecimentos, pensamentos e respostas pautadas nas vivências práticas; é importante fazê-los avançar, problematizando e assim avançar nas suas reflexões, conhecimentos e argumentação. É o que Paulo Freire nos chama a atenção para o movimento de procura e de análise da curiosidade ingênua à curiosidade epistemológica (FREIRE, 1998, p. 86, grifos nossos).

Outro episódio interessante ocorreu também com o Antônio, porteiro da escola. Ele se sentia muito incomodado e dizia ter muita raiva dele mesmo (usou várias vezes essa expressão) porque não sabia ler e escrever e "via aquele mundo de crianças sabendo ler e escrever" e ele não sabia. Esse foi o motivo que o levou até o PROEF1. Aluno do Kildrey (um dos poucos bolsistas do sexo masculino), passados uns dois meses, Sr. Antônio procurou a coordenação do PROEF da UFMG para dizer que estava muito feliz porque estava gastando apenas um lápis por semana; antes chegou a gastar três em apenas uma semana. Ao analisar com cautela tal narrativa, e passado o susto!, resta fazer algumas indagações: O que estaria Kildrey fazendo em sala de aula? E as discussões e reuniões semanais de planejamentos? Ao pedir ao Sr. Antônio que explicasse o que estava acontecendo, ele tranquilamente disse que agora já estava sabendo usar o lápis. No início, colocava tanta força que, mal começava a escrever, a ponta se quebrava; agora já estava dominando a ferramenta. Esse episódio nos remete aos personagens Pé-de-Meia, cabo eleitoral, e o roceiro João Francisco de Oliveira, em Vila dos Confins, de Mario Palmério: 
Caneta e lápis são ferramentas muito delicadas. A lida é outra, labuta pesada de sol a sol. (...) Pé de Meia: - Já varamos um eito. Vamos descansar um pouco: ainda falta o Francisco, falta o de Oliveira... Não é fácil, não senhor, leva tempo. Mas aos poucos João Francisco aprende a relaxar a mão, descobre que não carece de fazer tanta força, já não molha de suor o papel. (PALMÉRIO, 1974, p.63).

Esses e outros episódios, nós pesquisadores de EJA, utilizamos para refletirmos sobre as representações e os diferentes lugares que a escola ocupa na vida de nossos alunos não só do PROEF1 e da UFU. Assim como os usos dos utensílios, tão naturalizados para nós, para eles são como fetiches.

O aprendizado da leitura e da escrita ocorre nos tempos de cada um. Para alguns, o tempo é mais longo. Temos alunos que estão no PROEF1 há 4 anos na turma de alfabetização. Na UFU temos alunos que estão conosco há 10 anos e não querem ir embora. Para muitos desses idosos, o aprendizado é longo, a memória apresenta falhas. Processar as informações demanda muito esforço mental. E o período de férias ou até mesmo um feriado prolongado causam muita ansiedade nas monitoras, principalmente nas novatas. Tem-se a impressão de que eles desaprenderam o que já havia dado como aprendido. É necessário dizer sempre aos monitores e também aos alfabetizandos que é preciso exercer o exercício da paciência, tão necessária na EJA.

Barreto (2006) afirma que é equivocada a crença de que é necessário aprender antes para depois fazer, pois aprendemos fazendo e refletindo sobre o que fazemos, por isso o processo de vivenciar práticas do ensino de EJA com os alunos do curso de Pedagogia é tão necessário e enriquecedor para a formação de professores, e o projeto "EJA - em espaços não escolares" da UFU por mais de 12 anos, tem nos proporcionado esses aprendizados tão significativos para a nossa formação.

Um aspecto sempre trabalhado com as monitoras do PROEF1 e também com os estagiários da UFU é a relação de dependência que os alunos têm com eles, o que agrada muito às monitoras iniciantes e estagiários, mas logo vamos alertando-as no sentido de favorecer a autonomia dos alunos. Em geral, são extremamente dependentes do aval do monitor/estagiário: "está certo o que fiz?" Isso é o que mais se ouve durante as aulas. São inseguros, carentes e é preciso ajudá-los a conscientizar-se de como a aprendizagem se realiza.

Quanto ao trabalho de coordenação, é preciso ressaltar que é expressivo o número de bolsistas que fizeram parte da história do Programa de EJA na UFMG, pois a cada ano a PróReitoria de Extensão disponibiliza ao Programa 46 bolsas, distribuídas entre os três Projetos $-1^{\circ}$ segmento, $2^{\circ}$ segmento e ensino médio. Ao longo de 33 anos, tivemos em torno de 1.300 alunos da UFMG participantes do Programa. Dada a natureza do segmento, o PROEF1 conta com sete bolsistas anuais e tivemos 154 bolsistas. Diferentemente dos estágios que são realizados nas licenciaturas, no Programa de EJA/UFMG eles atuam como professores de EJA dentro de sua formação ${ }^{10}$. Os problemas, desafios, dificuldades, desconhecimentos téoricos-metodológicos, os planejamentos, os diagnósticos, as avaliações, tudo o que diz respeito ao desenvolvimento do trabalho é assumido por todo o grupo de monitores e coordenação ${ }^{11}$.

Para a grande maioria dos bolsistas da UFMG e estagiários da UFU, atuar nesses espaços como monitor ou como estagiário é a primeira experiência com a docência, e dar continuidade à atuação no campo da EJA, seja como professores, desenvolvendo suas

\footnotetext{
${ }^{10}$ No primeiro segmento prevalece a unidocência, isto é um monitor atua em todas as áreas, no segundo e terceiro os bolsistas são selecionados em função da formação e área de conhecimento.

11 No PROEF1 há uma coordenadora geral, enquanto nos demais - PROEF 2 e PROEMJA - os coordenadores são por área de conhecimento.
} 
pesquisas de mestrado e doutorado, tem sido nos últimos anos um caminho trilhado por alguns monitores do Programa. Entretanto, a experiência vivida pelos estudantes no Programa e no projeto são consideradas, pela maioria dos ex-monitores e ex-estagiários, um aprendizado e uma formação na EJA que não está presente no currículo dos cursos, tais como as leituras da obra de Paulo Freire, as propostas de projetos interdisciplinares, o trabalho coletivo, as histórias e o aprendizado com os alunos da EJA, que fazem dessa atuação no Programa da UFMG e no projeto da UFU um diferencial enquanto profissionais.

São muitos os fatos presenciados, vivenciados e ouvidos nas salas de aula do PROEF pelos alunos, nas reuniões de formação pelas monitoras e estagiárias: e o que temos feito, ao longo dos anos, à frente da coordenação desses projetos? Na UFMG podemos afirmar que o trabalho de ensino, extensão e pesquisa é fruto de muitas parcerias e cumplicidade entre nós - monitoras, alunos, coordenação - aprendemos e erramos juntos. Na UFU nossa carreira foi construída tendo como base a extensão e o ensino e, aos poucos, a pesquisa se fez necessário não só para a coordenação, mas principalmente para as estagiárias que atuaram ao longo desses 12 anos.

Acompanhar a trajetória de formação de nossos alunos da graduação à pós-graduação, estejam eles atuando em nossos projetos, é uma devolutiva que temos, e mais gratas ficamos quando nossas bolsistas de iniciação científica de extensão continuam sua formação acadêmica dentro do campo e/ou temática onde atuamos. Muitos ex-monitores são professores da rede pública atuantes na EJA, e alguns já são nossos colegas de universidade.

Olhando retrospectivamente vemos que o Programa de EJA da UFMG vem se constituindo numa referência no campo da alfabetização, na formação de pedagogos e de licenciados da UFMG, e, como campo de pesquisa, mantendo, assim, as ideias defendidas pelos professores pesquisadores pioneiros. Além de proporcionar uma oportunidade de escolarização aos jovens e adultos, o Programa tem despertado nos monitores o interesse em desenvolver seus projetos de mestrado e doutorado na área de alfabetização de jovens e adultos, assim como de produzir conhecimento sobre a EJA, participar dos eventos promovidos nessa área e inserir como professores coordenadores de EJA em diferentes instituições educacionais, públicas, privadas, em todos os segmentos da educação.

Um pouco diferente da UFMG, uma referência no campo da alfabetização, leitura e escrita, a UFU vem se constituindo de forma ainda incipiente no campo da EJA, e a partir de 2014, a UFU passou a ofertar cursos de pós-graduação latu sensu com ênfase na EJA.

A escolarização, responsável pela alfabetização e ampliação de repertórios de práticas sociais de uso da língua escrita, deve ser um processo do qual todos precisam participar, independente do momento de vida em que estejam, da condição social, de sexo, de etnia, do grupo a que pertencem, dos locais onde residem, de sua ocupação e renda. Portanto, é fundamental reconhecer que o tratamento desse tema, no Brasil, implica adentrar-se num campo político complexo, marcado pela desigualdade. Distinguir a necessária reinvenção da educação escolar a fim de minimizar desigualdades, reconhecer, valorizar diferenças e desconstruir dicotomias são tarefas centrais no campo da educação de pessoas jovens e adultas e de responsabilidade de variados atores, políticos e gestores, passando por profissionais da educação e pesquisadores, incluindo os próprios sujeitos a quem essa modalidade de educação é de direito.

A História da EJA, em especial da alfabetização de jovens e adultos, nas universidades públicas, no campo da extensão, ensino e pesquisa nos revelam que ainda temos muito o que fazer no campo da EJA: que o direito sempre negado às pessoas analfabetas não será equacionado enquanto a sociedade em geral tiver uma atuação preconceituosa e a academia, "um olhar entre aspas". Numa sociedade em que tantas desigualdades imperam, e que os preconceitos, por mais que sejam combatidos, insistem em permanecer, há que se pensar numa educação de jovens e adultos que possibilite um novo jeito de ser e estar no mundo, uma educação que seja de fato direcionada a esses alunos e que considere a sua realidade. 


\section{Referências}

BARRETO, Vera. Formação permanente ou continuada. In: SOARES, Leôncio (Org). Formação de educadores de jovens e adultos. Belo horizonte: UNESCO, 2006.

BARROS, José D’Assunção. O campo da história: especialidades e abordagens. Petrópolis: Vozes, 2004.

BERNARDES, Fernanda Afonso. Modos de formar professores de EJA: 1990-2006. 2016. Dissertação (Mestrado em Educação) - Faculdade de Educação, Universidade Federal de Uberlândia, Uberlândia, 2016.

FONTANA, Roseli A. C. Como nos tornamos professoras? Belo Horizonte: Autêntica, 2003.

FREIRE, Paulo. Extensão ou Comunicação?. 7ª edição. São Paulo: Editora Paz e Terra, 1985.

FREIRE, Paulo. Pedagogia da Autonomia. São Paulo: Editora Paz e Terra. 1988.

GADOTTI, Moacir. Por uma política nacional de educação popular de jovens e adultos. São Paulo: Moderna: Fundação Santillana, 2014.

GADOTTI, Moacir; ROMÃO, José E (Orgs.). Educação de jovens e adultos: teoria, prática e proposta. $2^{\mathrm{a}}$ ed. rev. São Paulo: Cortez, Instituto Paulo Freire, 2000.

HADDAD, Sergio. Novos caminhos em educação de jovens e adultos. São Paulo: Global, 2007.

KLEIMAN, Angela B. Modelos de letramento e as práticas de alfabetização na escola. In: KLEIMAN, Angela B. (Org.). Os Significados do letramento: uma nova perspectiva sobre a prática social da escrita. Campinas: Mercado de letras, 1995.

KLEIMAN, Angela B. O processo de aculturação pela escrita: ensino da forma ou aprendizagem da função? In: KLEIMAN, A.B; SIGNORINI, I. (orgs.). O ensino e a formação do professor: alfabetização de jovens e adultos. Porto Alegre: Artmed, 2000.

LEPICK, Vanessa. Formação inicial de alfabetizadoras para a educação de jovens e adultos em Minas Gerais (1996-2006). 2018. Tese (Doutorado em Educação) - Faculdade de Educação, Universidade Federal de Uberlândia, Uberlândia, 2018.

MACIEL, Francisca. Memorial. Documento apresentado à Faculdade de Educação da UFMG como requisito parcial para progressão funcional à classe de Professor Titular. Belo Horizonte: UFMG, 2018.

MACIEL, Francisca. O analfabeto: vida e lida sem escrita. Belo Horizonte: UFMG, 1994.

PALMERIO, Mário. Vila dos Confins. 16ª ed. Rio de Janeiro, José Olympio, 1974.

SANTOS, Sônia Maria. Memorial. Documento apresentado à Faculdade de Educação da UFU como requisito obrigatório para progressão à classe de Professor Titular da FACED/UFU, Uberlândia/MG, 2016.

SANTOS, Sônia Maria; SILVA, Fernanda Aparecida Oliveira Rodrigues; LEPICK Vanessa; ARAÚJO Regina Magna Bonifácio. Fóruns EJA do Brasil: Minas Gerais na defesa da educação de jovens e adultos. In: SILVA, Otavio Henrique Ferreira; PILOTO, Sumika Soares de Freitas Hernandez; CARA, Daniel Tojeira (Orgs). Fóruns de Educação no Brasil. Rio de Janeiro: Dictio Brasil, 2016.

SOARES, Leôncio. 30 Anos da EJA na UFMG - Extensão, Formação e pesquisa. Revista Teias, v. 17, Edição Especial - Práticas nas IES de formação de professores para a EJA, Rio de Janeiro, 2016. https://doi.org/10.12957/teias.2016.25013

SOARES, Magda. Metamemória-memórias: travessia de uma educadora. São Paulo: Cortez, 2001.

SOARES, Magda. Universidade, cidadania e alfabetização. Revista UFMG, Belo Horizonte, 2003.

UNESCO, BRASIL. Ministério da Educação, Secretaria de Educação Continuada, Alfabetização e Diversidade. Primeiro Encontro Nacional de Alfabetização e Cultura Popular em Recife, 1963. Brasília: UNESCO, 2009. 